Article

\title{
Performance and Long Term Stability of Mesoporous Silica Membranes for Desalination
}

\author{
Muthia EIma, Christelle Yacou, João C. Diniz da Costa and David K. Wang * \\ FIMLab - Films and Inorganic Membrane Laboratory, School of Chemical Engineering, \\ The University of Queensland, Brisbane, Queensland 4072, Australia; \\ E-Mails: m.elma@uq.edu.au (M.E.); c.yacou@uq.edu.au (C.Y.); j.dacosta@uq.edu.au (J.C.D.C.) \\ * Author to whom correspondence should be addressed; E-Mail: d.wang1@uq.edu.au; \\ Tel.: +61-7-3365-9760; Fax: +61-7-3365-4199.
}

Received: 17 June 2013; in revised form: 2 July 2013 / Accepted: 3 July 2013 /

Published: 12 July 2013

\begin{abstract}
This work shows the preparation of silica membranes by a two-step sol-gel method using tetraethyl orthosilicate in ethanolic solution by employing nitric acid and ammonia as co-catalysts. The sols prepared in $\mathrm{pH} 6$ resulted in the lowest concentration of silanol $(\mathrm{Si}-\mathrm{OH})$ species to improve hydrostability and the optimized conditions for film coating. The membrane was tested to desalinate $0.3-15 \mathrm{wt} \%$ synthetic sodium chloride $(\mathrm{NaCl})$ solutions at a feed temperature of $22{ }^{\circ} \mathrm{C}$ followed by long term membrane performance of up to $250 \mathrm{~h}$ in $3.5 \mathrm{wt} \% \mathrm{NaCl}$ solution. Results show that the water flux (and salt rejection) decrease with increasing salt concentration delivering an average value of $9.5 \mathrm{~kg} \mathrm{~m}^{-2} \mathrm{~h}^{-1}(99.6 \%)$ and $1.55 \mathrm{~kg} \mathrm{~m}^{-2} \mathrm{~h}^{-1}(89.2 \%)$ from the 0.3 and $15 \mathrm{wt} \%$ saline feed solutions, respectively. Furthermore, the permeate salt concentration was measured to be less than $600 \mathrm{ppm}$ for testing conditions up to $5 \mathrm{wt} \%$ saline feed solutions, achieving below the recommended standard for potable water. Long term stability shows that the membrane performance in water flux was stable for up to $150 \mathrm{~h}$, and slightly reduced from thereon, possibly due to the blockage of large hydrated ions in the micropore constrictions of the silica matrix. However, the integrity of the silica matrix was not affected by the long term testing as excellent salt rejection of $>99 \%$ was maintained for over $250 \mathrm{~h}$.
\end{abstract}

Keywords: mesoporous; silica; membrane; sol-gel; desalination; stability 


\section{Introduction}

Water scarcity is a serious global issue that is exacerbated by increasing global population, rising seawater level and disappearing freshwater aquifers and reservoirs. Literally, around $97 \%$ of the world's water exceeds the potable water quality which cannot be consumed or even be used for agricultural purposes [1,2]. Hence, sourcing potable water from sea water, a process called desalination, is a logical way ahead to address the water requirements of the current and future needs of our society. Desalination of salty waters (brackish, seawater and brine water) can be carried out by membrane separation processes such as reverse osmosis (RO), membrane distillation (MD) or pervaporation (PV). In particular, RO using polymeric membranes are now the most widely applied membrane separation technology for desalination around the world. For instance, large desalination plants have been built in Spain, Australia, Saudi Arabia and United Arab of Emirates [3]. Although RO is the most energy efficient process for water desalination to date, it relies on a pressure-driven solution-diffusion process of separating fresh water via a dense membrane which often suffers from polymer swelling, biofouling, scaling and poor thermal and chemical resistance [4,5].

Inorganic membranes have recently attracted the attention of the research community and industry owing to robustness, long life-span and better resistance to extrinsic environmental and industrial factors. Currently, there are two types of widely researched inorganic silica membranes for desalination, namely zeolites [6-8] and amorphous silica membranes [9-11]. Zeolite membranes have proven to be effective but their long term stability and scale up still present an on-going issue [8]. Silica membranes have excellent molecular sieving properties and a simpler fabrication process via sol-gel processing, though they need functionalisation to overcome hydro-instability. The structures of silica membranes have pore sizes in the range of 3-5 $\AA$ on the order of the kinetic diameter of the water molecule $\left(\mathrm{d}_{\mathrm{k}}=2.6 \AA\right)$, thus ideal to hinder the passage of hydrated salt ions (e.g., $\mathrm{Na}^{+}: \mathrm{d}_{\mathrm{k}}=7.2 \AA$ and $\left.\mathrm{Cl}^{-}: \mathrm{d}_{\mathrm{k}}=6.6 \AA\right)$. Therefore, silica membranes separate water from salts by a molecular sieving mechanism [12]. Overall, the interest in amorphous silica based membranes derived from sol-gel is gaining research momentum particularly the effort is emphasized on improving their membrane performance and hydrothermal stability [10].

Owing to the affinity of these membranes for water adsorption which leads to structural degradation and a loss of selectivity, several research strategies have been employed to overcome hydro-instability. These include carbonized templating [9,13], metal doping [11,14-18] and hybrid organosilica [19-21] methods. These strategies concertedly attempt to modify the surface properties of silica in order to minimize the interaction of water molecules with the surface silanol groups ( $\mathrm{Si}-\mathrm{OH})$. However, the water fluxes reported by these works are generally too low and research in this area is still at its infancy. In order to address these problems, it becomes important to reduce the level of silanol concentrations in the silica matrix to produce an improvement in the structural stability and water flux. In addition, these silica base membranes have been prepared by acid catalyzed sol-gel method with low $\mathrm{pH}$ of generally below 2.5. At these conditions, amorphous silica structures with molecular sieving domains are formed, though the sol-gel synthesis favours the production of silanol species.

In this work we modified the sol-gel process to reduce the amount of silanol groups. This was achieved by a two-step sol synthesis, where the first step followed a traditional acid catalysis and the second step included $\mathrm{pH}$ modification using ammonia base catalysis to favour the condensation of 
silanols to siloxane bridges $(\mathrm{Si}-\mathrm{O}-\mathrm{Si})$. The latter is known to oppose hydro-instability in silica membranes [16,22,23]. To demonstrate this concept, silica films were coated on alumina substrates and membranes were tested. The morphology and long term operation and stability are reported along with the xerogels characterization by FTIR and $\mathrm{N}_{2}$ sorption.

\section{Experimental Section}

\subsection{Materials and Membrane Synthesis}

Silica sols were synthesized by a two-step sol-gel process employing acid and base as catalysts. Tetraethyl orthosilicate (TEOS, 99.0\%, (GC) Sigma-Aldrich) was added drop-wise into ethanol (EtOH, 99\%) and stirred for $5 \mathrm{~min}$ in ice bath condition at $0{ }^{\circ} \mathrm{C}$ to avoid partial hydrolysis followed by the addition of diluted nitric acid (0.0008 $\mathrm{M} \mathrm{HNO}_{3}$, Merck). The sol mixture was refluxed for $1 \mathrm{~h}$ at $50{ }^{\circ} \mathrm{C}$ under vigorous stirring to achieve a complete hydrolysis of the alkoxy groups. Ammonia solution $\left(\mathrm{NH}_{3}, 25 \%\right.$, Merck) diluted in ethanol was added drop wise into sol mixture to commence the condensation reaction and reflux was continued for another $2 \mathrm{~h}$ to obtain the resultant sol which was then dried in a temperature controlled oven at $60{ }^{\circ} \mathrm{C}$ for $24 \mathrm{~h}$ to obtain the dried gel. The final molar ratios of the TEOS:EtOH:HNO $3: \mathrm{H}_{2} \mathrm{O}: \mathrm{NH}_{3}$ sol were calculated to be 1:38:0.0007:5:x, where $x$ was varied from $0.003,0.008,0.02$ and 0.08 to prepare the final sol $\mathrm{pH}$ of 6 to $9 \pm 0.1$. The dried gel was grounded into powder and calcined in a temperature controlled furnace in air at $600{ }^{\circ} \mathrm{C}$ for $4 \mathrm{~h}$ with $1^{\circ} \mathrm{C} \min ^{-1}$ ramping and cooling rates.

Thin membrane films were coated on macroporous alumina substrates $\left(\alpha-\mathrm{Al}_{2} \mathrm{O}_{3}\right.$ tubular support ( $\Phi_{\text {pore size }} \approx 100 \mathrm{~nm}$ ), Ceramic Oxide Fabricates, Australia) using the resultant sol prepared at pH 6 via a dip-coating process with a dwell time of $2 \mathrm{~min}$ and a dipping and withdrawal rate of 10 and $5 \mathrm{~cm} \mathrm{~min}^{-1}$, respectively. After the deposition of each layer, the membrane layer were dried briefly in an oven and then calcined in a furnace according to the same treatment described above for the xerogels. This cycle of dip-coating, drying and calcination was repeated four times for a total of four membrane layers.

\subsection{Materials and Membrane Characterisation}

Nitrogen physisorption analysis at $77 \mathrm{~K}$ and 1 bar were conducted using Micromeritic TriStar 3020 instrument. Sample was degassed under vacuum for $>6 \mathrm{~h}$ at $200{ }^{\circ} \mathrm{C}$. The specific surface area was determined from Brunauer, Emmett and Teller (BET) method and total pore volume was taken from the last point of the isotherm. Dubinin-Astakhov and Barrett-Joyner-Halenda methods were taken to determine the average pore sizes of microporous and mesoporous materials, respectively. The analysis of pore size distribution was obtained using the density functional theory (DFT) method for pore sizes between 1 to $50 \mathrm{~nm}$ for micropore and mesopore range [24-27]. Fourier Transform Infra-Red (FTIR) spectra data were collected at a resolution of $4 \mathrm{~cm}^{-1}$ in the range of $4000-600 \mathrm{~cm}^{-1}$ for a total of 30 scans using Shimadzu IR affinity-1 with a Pike MIRacle ATR attachment. Peak deconvolution of the absorption bands over the region $1300-600 \mathrm{~cm}^{-1}$ was performed with FityK software using Gaussian lineshapes with the least square fit routine [28] and peak areas were measured for the 
normalized spectra using a local baseline. The membrane morphology and thickness were characterized by field emission scanning electron microscopy (FESEM JOEL 7001).

\subsection{Membrane Desalination and Long Term Stability}

The membrane was assembled into a classical pervaporation set-up for desalination experiments as shown in Figure 1. Briefly, the membrane tube was blocked at the bottom side (dead end mode) and immersed in the tank containing a saline feed solution which was open to atmospheric condition. The temperature $\left(22 \pm 1^{\circ} \mathrm{C}\right)$ of the feed solution was maintained at room temperature and monitored by a thermometer. The feed tank was then connected to a peristaltic pump where the retentate stream was constantly recycled and stirred to prevent concentration polarization on the feed side of the membrane. The membrane was connected to a vacuum line and the permeate stream was collected in a cold trap which was immersed in a liquid nitrogen dewar.

Figure 1. Desalinating rig using a customised pervaporation set up.

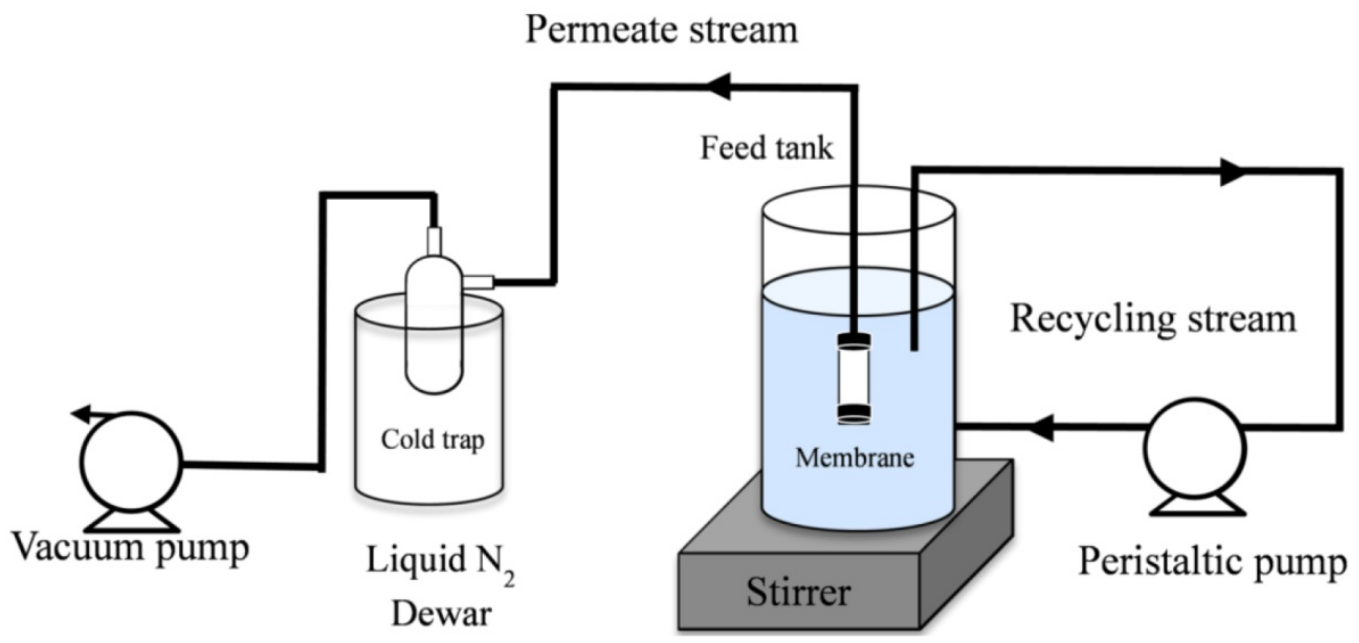

To prepare the saline feed solution, the powder of sodium chloride ( $\mathrm{NaCl}$, Sigma Aldrich) were dissolved in deionised water to prepare the salt solution concentrations ranging from 0.3 to $15 \mathrm{wt} \%$. The water flux, $\mathrm{F}\left(\mathrm{kg} \mathrm{m}^{2} \mathrm{~h}^{-1}\right)$, was determined based on the Equation $\mathrm{F}=m /(A \cdot \Delta t)$, where $m$ is the mass of permeate $(\mathrm{kg})$ retained in the cold trap, $A$ is the surface-active area $\left(\mathrm{m}^{2}\right)$ and $\Delta t$ is the time measurement (h). The salt rejection, $\mathrm{R}(\%)$, was calculated as $\mathrm{R}=\left(C_{f}-C_{p}\right) / C_{f} \times 100 \%$, where $C_{f}$ and $C_{p}$ are the feed and permeate concentrations of salt (wt \%). Conductivities of the retentate and permeate solutions were determined by using a conductivity meter (labCHEM CP). Lastly, long term membrane performance for hydrostability was conducted in a $3.5 \mathrm{wt} \%$ feed $\mathrm{NaCl}$ solution at $22{ }^{\circ} \mathrm{C}$.

\subsection{Error Analysis}

The data represents the mean of six permeate sample solutions from two identical membranes with two standard deviations from the mean representing a 95\% confidence interval. 


\section{Results and Discussion}

\subsection{Xerogel Characterisation}

The FTIR spectra of the calcined xerogel samples in Figure 2a show very similar vibrational bands in the region of 1400-700 $\mathrm{cm}^{-1}$ for all samples independently of their $\mathrm{pH}$. First of all, the intense peak near $1070 \mathrm{~cm}^{-1}$ along with bands of lesser intensity at 1160,1030 and $800 \mathrm{~cm}^{-1}$ are all assigned to various stretching and bending vibrations of the siloxane ( $\mathrm{Si}-\mathrm{O}-\mathrm{Si}$ ) groups [29]. The other peak of interest appearing at the peak at $960 \mathrm{~cm}^{-1}$ is attributed to the vibrational stretching of the silanol (Si-OH) groups. A scan of the spectral profiles also suggests that the chemical constituents are quite similar in all the samples. The change of the vibrational bands relating to the silanol and siloxane concentration was quantitatively assessed by a deconvolution of the bands at 960 and $1070 \mathrm{~cm}^{-1}$, respectively. The peak area ratio analysis regarding the silanol versus the siloxane groups is presented in Figure $2 b$. The results show that this ratio increases as $\mathrm{pH}$ is increased but then decreases again at pH 8 down to a minimum observed at $\mathrm{pH}$ 9. This behaviour could be explained on the basis of the $\mathrm{pH}$-dependency of the hydrolysis, condensation and polymerization reactions for TEOS system as has been reported extensively by Brinker et al. [30-32]. These results clearly indicate that the lowest silanol concentrations, or likewise the highest siloxane bridge concentrations, were achieved with calcined xerogels prepared with $\mathrm{pH} 6$ or 9 .

Figure 2. (a) FTIR spectra of the calcined silica xerogels and (b) the peak area ratio of the silanol peak at $960 \mathrm{~cm}^{-1}$ against the siloxane peak at $1070 \mathrm{~cm}^{-1}$ for the spectra as a function of the sol $\mathrm{pH}$.
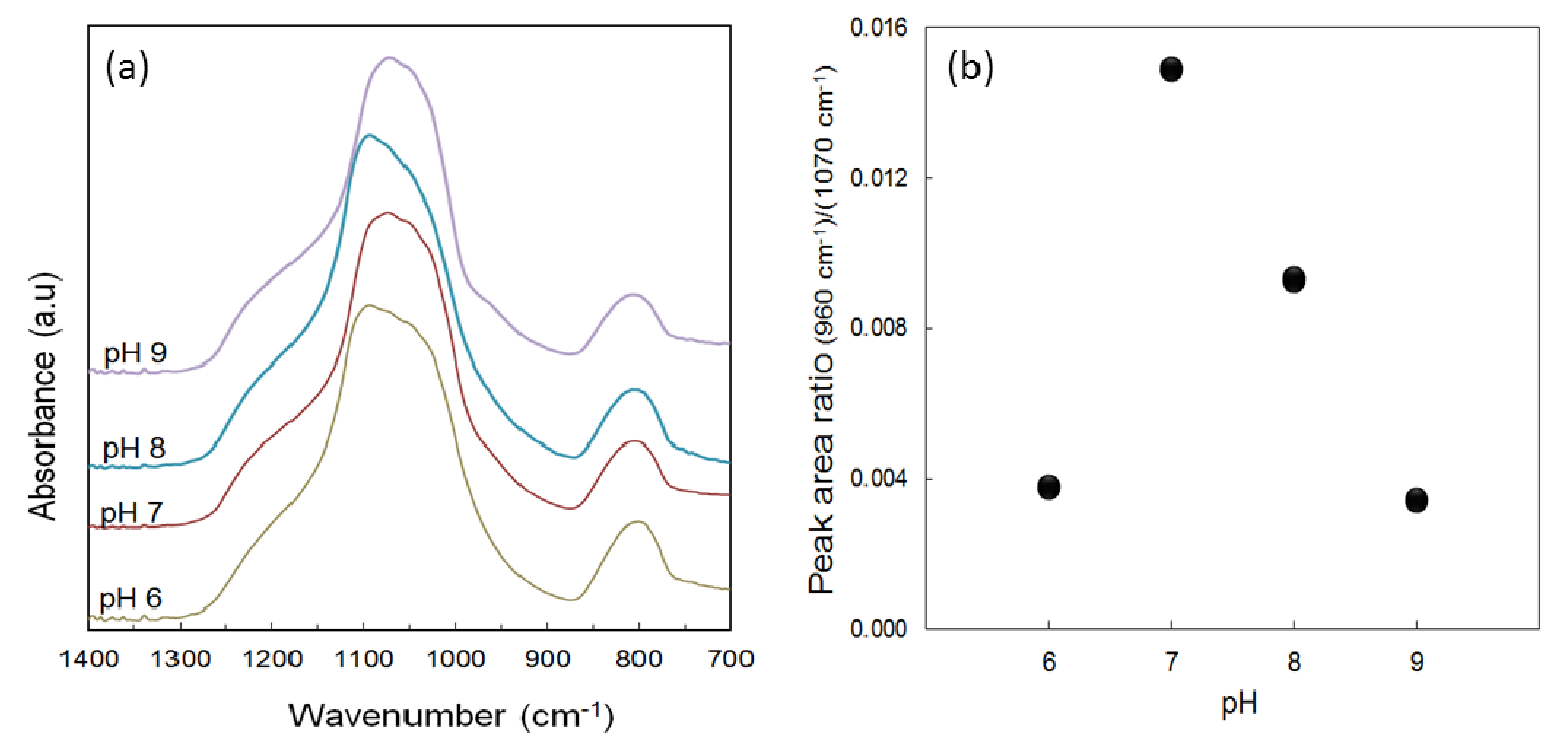

In a two-step, acid-base, sol-gel process, the first step was carried out under an acidic condition $(\mathrm{pH} \sim 4)$ under reflux. Acid catalyzed hydrolysis with heating promoted a high production of silanol species from the silane precursor. When $\mathrm{pH}$ of the sol is adjusted by the addition of the ammonia hydroxide in the second step, the sol $\mathrm{pH}$ increases rapidly to greater than 4 , which is much higher than the isoelectric point boundary ( $\mathrm{pH} 1-3$ ) of the silica species [30]. At this instance, the silanol species are expected to be all deprotonated participating in the polycondensation reaction generating a large 
concentration of highly condensed species (e.g., siloxane bridges) as shown by the lower peak ratio in the case of $\mathrm{pH} 6$ (Figure 2b). At near neutral $\mathrm{pH}$ of 7, there appears to be another boundary because of the solubility and dissolution of the formed silica are maximized as silica is much more soluble in alkaline solutions than in acidic ones [30,31]. In this sample, hydrolysis occurs preferentially on the monomers and the weakly branched oligomers that subsequently condense preferentially with the silica clusters leading to a higher degree of uncondensed silanol species [30], and this is indicated by the highest peak area ratio for this sample. The mechanism of structural formation in this case is strongly governed by a monomer-cluster growth that favours a more compact structure. Above the pH 7, polymerization typically occurs via Ostwald ripening. Particles grow even more rapidly under the refluxing condition and the weakly cross-linked polymers formed in the first hydrolysis step tend to be dissolved and then re-precipitate on the more highly condensed sites [31,32], as this was observed by a fast onset of gelation in the $\mathrm{pH} 9$ sample. Hence, the observed silanol/siloxane ratio decreases from $\mathrm{pH} 7$ thereafter.

The surface and pore properties of the bulk silica xerogels were analyzed by $\mathrm{N}_{2}$ sorption technique which provides important qualitative information regarding the microstructure of the resulting molecular sieving membranes. In general, pore sizes with diameters greater than $50 \mathrm{~nm}$ are classified as macroporous; between 2 and $50 \mathrm{~nm}$ are mesoporous and smaller than $2 \mathrm{~nm}$ are microporous. The $\mathrm{N}_{2}$ sorption isotherms for the xerogel samples are shown in Figure 3 and BET surface areas, total pore volumes and average pore diameters are listed in Table 1.

Figure 3. Plot of $\mathrm{N}_{2}$ sorption isotherms for the calcined xerogels.

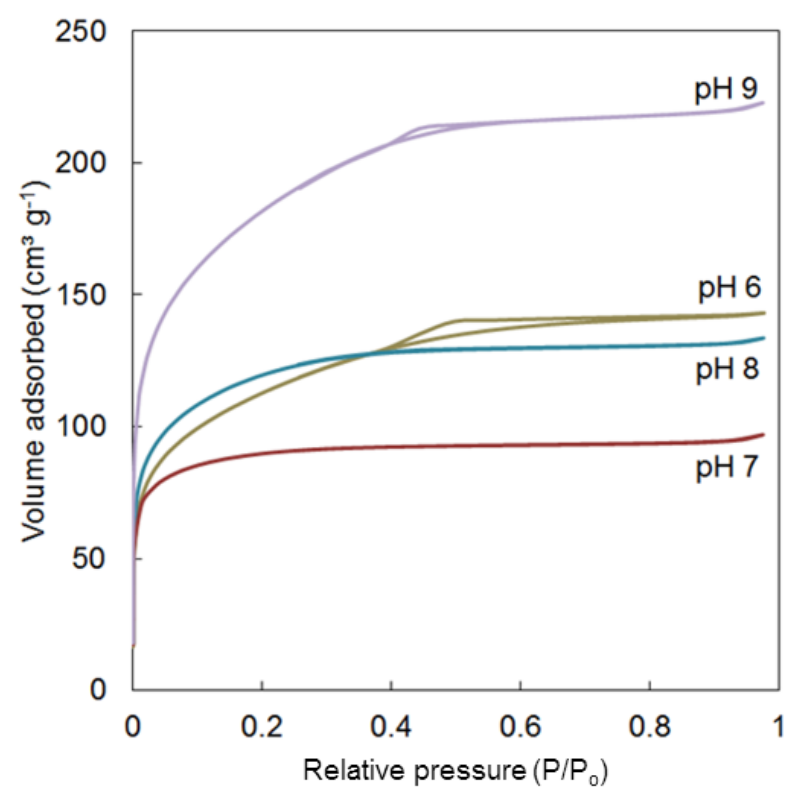

Table 1. Surface properties of the bulk silica xerogels.

\begin{tabular}{cccc}
\hline Sol $\mathbf{~ p H}$ & $\begin{array}{r}\text { BET surface area } \\
\left(\mathbf{m}^{\mathbf{2}} \mathbf{g}^{-\mathbf{1}}\right)\end{array}$ & $\begin{array}{c}\text { Total pore volume } \\
\left(\mathbf{c m}^{\mathbf{3}} \mathbf{g}^{\mathbf{- 1}}\right)\end{array}$ & $\begin{array}{c}\text { Average pore } \\
\text { diameter }(\mathbf{n m})\end{array}$ \\
\hline 6 & 402 & 0.221 & 2.70 \\
7 & 415 & 0.150 & 1.76 \\
8 & 425 & 0.207 & 1.93 \\
9 & 649 & 0.345 & 2.60 \\
\hline
\end{tabular}


The isotherm profiles of the xerogels prepared at different sol pHs show a very different behaviour even though various proportions of microporosity/mesoporosity are present in all the samples. Xerogels prepared in $\mathrm{pH} 6$ and 9 show a tendency to form micro and mesoporous materials as the adsorption saturation was achieved above $0.65 \mathrm{P} / \mathrm{P}_{0}$ with the capillary condensation leading to hysteresis near $0.5 \mathrm{P} / \mathrm{P}_{0}$. Their respective average pore diameters are measured around 2.6-2.7 nm. These results corroborated with a higher amount of siloxane bridges shown in Figure $2 \mathrm{~b}$. On the other hand, samples prepared at $\mathrm{pH} 7$ and 8 produced a Type I isotherms with no hysteresis, characteristics of a typical microporous material. Their BET surface areas $\left(\sim 420 \mathrm{~m}^{2} \mathrm{~g}^{-1}\right)$ and total pore volumes $\left(\sim 0.18 \mathrm{~cm}^{3} \mathrm{~g}^{-1}\right)$ are quite comparable with pore sizes of around $1.8 \mathrm{~nm}$. Hence, microporosity correlates well with a high concentration of silanol groups, and in line with previous reports on silica membranes $[11,18]$.

\subsection{Membrane Morphology}

Figure 4a,b display representative scanning electron microscope images of a synthesized silica membrane and the underlying alumina substrate. The cross section of the membrane shows that there is a lack of clear distinction between the top layer and the macroporous substrate layer. Without the intermediate layer, the top layer sol is expected to infiltrate deep into the macropores of the substrate where the intermingling between the two layers is unavoidable. The thickness of the silica layer is estimated to be $\sim 470 \mathrm{~nm}$ as shown by the inset of Figure $4 \mathrm{a}$. In fact, as evidenced by Figure $4 \mathrm{~b}$, the surface morphology of the membrane clearly shows that the roughness of the macroporous alumina substrate is translated onto the silica layer which basically followed the morphology of the substrate whereby the grain size of the $\alpha-\mathrm{Al}_{2} \mathrm{O}_{3}$ particles is estimated to be approximately $0.5 \mu \mathrm{m}$. Despite this, the surface morphology of the silica layer in the inset of Figure $4 \mathrm{~b}$ appears to be homogeneous without any major cracks or defects that would otherwise contribute to the poor membrane performance.

Figure 4. SEM images of the as-synthesized $\mathrm{pH} 6$ sol-gel derived membrane in (a) cross-section and (b) top surface with the inset images showing the close up of the respective morphology.
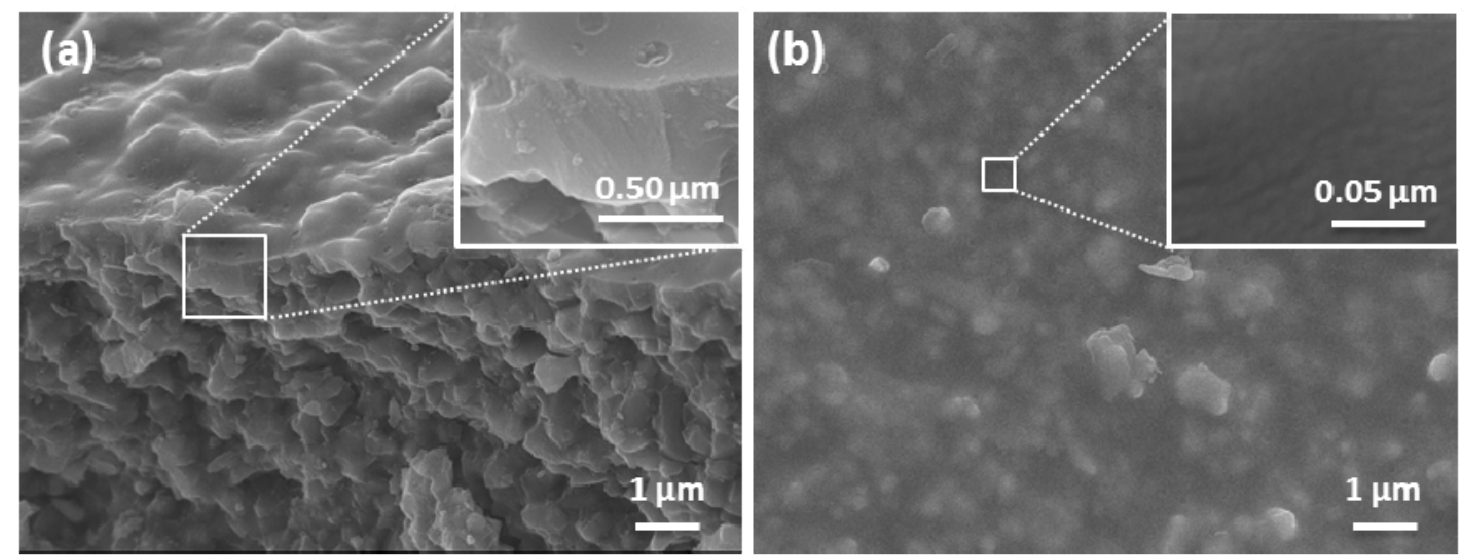

Conventionally silica films are coated on $\gamma-\mathrm{Al}_{2} \mathrm{O}_{3}$ interlayers (small pore sizes of $3-5 \mathrm{~nm}$ ) instead of substrates with $\alpha-\mathrm{Al}_{2} \mathrm{O}_{3}$ (larger pore sizes of 100-300 nm) [33-35]. This is the general approach for coating acid catalysed silica films [11,36,37], particularly to avoid cracking or defects in the top silica 
films. By changing the silica sol-gel synthesis, this work demonstrates for the first time that defect free silica films can be directly coated onto a macroporous substrate without any intermediate layer. This coating strategy is attractive as it reduces the number of layers - at least two interlayers are no longer required — and consequently reducing preparation time and production costs.

\subsection{Membrane Performance and Long Term Stability}

From these preliminary results and analyses, it was shown that the sample prepared by the pH 6 and 9 sol produced a relatively lower concentration of the surface hydrophilic silanol species. The $\mathrm{pH} 9$ sols precipitated very quickly, followed by gelation. Hence, $\mathrm{pH} 9$ sols were unsuitable for membrane preparation. Therefore, $\mathrm{pH} 6$ was chosen to directly dip-coat the macroporous $\alpha-\mathrm{Al}_{2} \mathrm{O}_{3}$ substrate without further priming with intermediate layers. Membrane performance in terms of water fluxes and salt rejections was evaluated in various salt feed concentrations $(\mathrm{NaCl} 0.3-15 \mathrm{wt} \%)$ at $22{ }^{\circ} \mathrm{C}$ as shown in Figure 5. The membranes were initially tested in pure water followed by increasing salt concentrations in order to simulate brackish $(0.3 \mathrm{wt} \%)$, sea $(3.5 \mathrm{wt} \%)$ to brine $(>5 \mathrm{wt} \%)$ waters. In Figure 5, the membranes delivered considerable high water fluxes of $9.5 \mathrm{~kg} \mathrm{~m}^{-2} \mathrm{~h}^{-1}$ and excellent salt rejections in excess of $99 \%$ for brackish $\mathrm{NaCl} 0.3 \mathrm{wt} \%$ concentration. The membrane performance decreased as a function of the salt concentration reaching a minimum of $2.8 \mathrm{~kg} \mathrm{~m}^{-2} \mathrm{~h}^{-1}(95 \%$ salt rejection) and $1.6 \mathrm{~kg} \mathrm{~m}^{-2} \mathrm{~h}^{-1}(89 \%)$ for the brine feed waters 7.5 and $15 \mathrm{wt} \%$, respectively.

The reduction of water fluxes with increasing the feed salt water concentration is mainly associated with the polarisation effect. As water permeates through the membrane, its concentration on the membrane surface reduces, consequently the concentration of salt increases on the membrane surface. This salt polarisation effect is controlled by chemical equilibrium, as an increase in salt at the membrane surface will result in water diffusing from the bulk feed solution to the membrane surface. Hence, the salt polarisation effect tends to limit the driving force for water permeation. A secondary effect is the blocking of pore size constrictions by large hydrated salt ions [11]. This is important as the xerogel samples in Figure 3 resulted in micro and mesoporous materials. Hence, percolative pathways in the amorphous matrix may be blocked by the larger hydrated salt ions.

In addition, the reduction of salt rejection as the salt feed concentration is closely associated with both salt polarisation effect and the structure of the $\mathrm{pH} 6$ silica membrane. As the feed salt concentration increases at the membrane surface, so does the polarisation effect. As a result, the driving force for salt diffusion increases across the membrane. The $\mathrm{pH} 6$ silica membrane also has mesopores as per Figure 3. If mesopores are linked together in the amorphous silica matrix, then there is a preferential percolative pathway favouring hydrated salt diffusion. Figure 5 shows that this is the case as salt was measured in the permeate stream, though the salt rejections were high. Hence, these results suggest that the concentration of mesoporous percolative pathways through the amorphous silica film is small.

The membranes prepared in this work performed favourably as compared to previous inorganic membranes reported in open literature as listed Table 2. For similar testing conditions ( $\mathrm{NaCl} 3.5 \mathrm{wt} \%$; $\left.22{ }^{\circ} \mathrm{C}\right)$, it is observed the $\mathrm{pH} 6$ silica membrane $\left(6.8 \mathrm{~kg} \mathrm{~m}^{-2} \mathrm{~h}^{-1} ;>98 \%\right.$ salt rejection) delivered a water flux 20 fold higher than cobalt oxide silica membrane $\left(0.35 \mathrm{~kg} \mathrm{~m}^{-2} \mathrm{~h}^{-1} ;>99.5 \%\right)$ [11], and at least 2 fold higher than microporous carbonized templated silica membranes $\left(1.9 \mathrm{~kg} \mathrm{~m}^{-2} \mathrm{~h}^{-1} ;>98 \%\right)$ [9] and 
mesoporous hybrid organosilica membranes $\left(3 \mathrm{~kg} \mathrm{~m}^{-2} \mathrm{~h}^{-1} ;>99.5 \%\right)[19,21]$, whilst salt rejections were high and comparable. In this body of work [9,11,19,21], the membranes were prepared via an acid-catalysed sol-gel process with relatively low $\mathrm{pH}$, as a result of which forms microporous silica thin films. Therefore, these membranes naturally produced lower water fluxes due to a higher concentration of microporous percolative pathways.

Figure 5. Membrane desalination performance in pervaporation mode as a function of the feed salt concentrations at $22{ }^{\circ} \mathrm{C}$. The water fluxes are shown in the vertical bars (left axis) and the salt rejection values are shown in the unfilled circles (right axis).

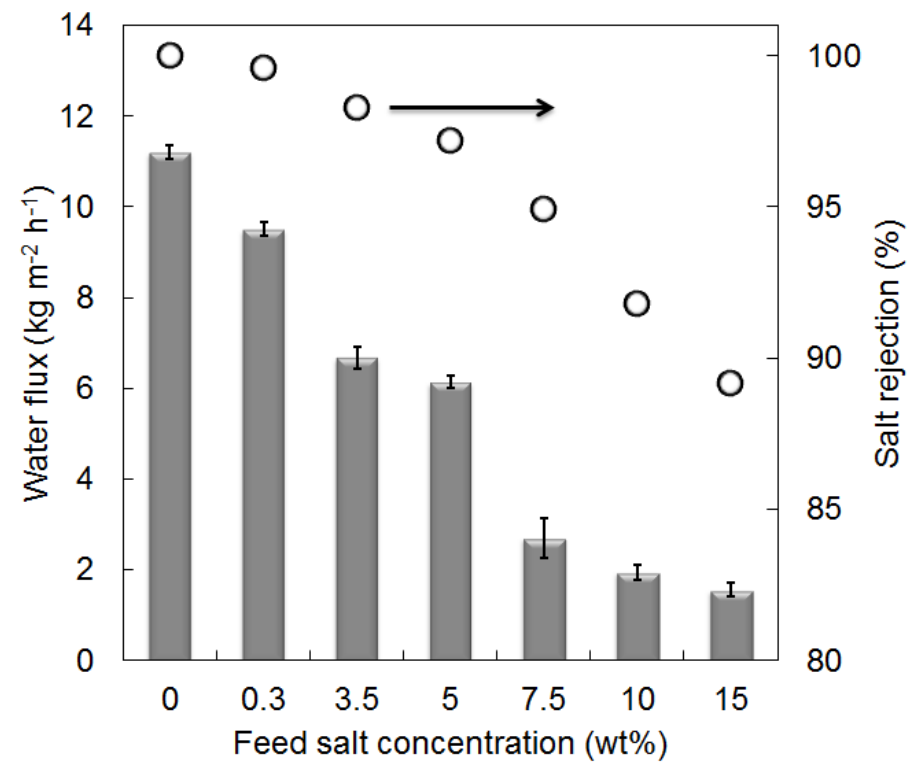

Remarkably, the ability of this membrane to process brine conditions of up to $15 \mathrm{wt} \%$ feed is very attractive with a much higher water flux than that is reported for metal oxide silica membrane [11], albeit with a lower rejection rate which can be overcome by a second pass filtration and/or further membrane development. One possible explanation for the higher fluxes produced by the membranes in this work could be that they were prepared without any intermediate layer which can also contribute to the water transport resistance, unlike the other reported membranes with several intermediate layers. Furthermore, when compared to zeolite-based membranes, the membrane performance of MFI-ZSM-5 [8] produced similar high water fluxes at low salt concentrations but trended oppositely as salt concentration increases. Despite that the MFI-ZSM-5 membrane produced much higher fluxes at $15 \mathrm{wt} \%$ feed, though the salt rejection was severely compromised due to poor membrane stability and dissolution of the charged double layer in the zeolitic pores. The major advantages of $\mathrm{pH} 6$ silica membrane are better desalination performance at mild testing conditions.

The purity of the permeate water was assessed by evaluating the salt concentration (parts per million) calculated from a standard curve based on the conductivity measurements. Figure 6 demonstrates that the permeate salt concentration was calculated to be 220 and 340 ppm for 3.5 and $5 \mathrm{wt} \%$ feed solutions, respectively. These are well below the recommended concentration of $600 \mathrm{ppm}$ (total dissolved salt) for potable water according to the World Health Organization [1]. These results clearly show that the silica membranes prepared in this work can be used to treat saline waters across a broad range of salt concentrations at the room temperature conditions with excellent performance. 
Table 2. Performance comparison of silica based membranes for desalination.

\begin{tabular}{|c|c|c|c|c|c|c|}
\hline \multicolumn{2}{|c|}{ Membrane type } & $\begin{array}{c}\text { Feed Temp. } \\
\left({ }^{\circ} \mathrm{C}\right)\end{array}$ & $\begin{array}{c}\text { Feed conc. range } \\
(w \mathrm{t} \%)\end{array}$ & $\begin{array}{l}\text { Water flux } \\
\left(\mathrm{kg} \mathrm{m}^{-2} \mathrm{~h}^{-1}\right)\end{array}$ & $\begin{array}{c}\text { Rejection } \\
(\%)\end{array}$ & Reference \\
\hline Pure silica & TEOS pH 6 & $22^{b}$ & $\begin{array}{c}0.3 \\
3.5-15\end{array}$ & $\begin{array}{c}9.5 \\
6.8-1.6\end{array}$ & $\begin{array}{c}99.6 \\
98-89\end{array}$ & This work \\
\hline $\begin{array}{l}\text { Carbonized } \\
\text { template }\end{array}$ & $\begin{array}{c}\text { Ionic C6 } \\
\text { Ionic } \mathrm{C} 16 \\
20 \mathrm{wt} \% \mathrm{PEG}-\mathrm{PPG}\end{array}$ & $\begin{array}{l}20^{a} \\
20^{b} \\
20^{b}\end{array}$ & $\begin{array}{c}0.3-3.5 * \\
0.3-3.5 \\
0.3-3.5\end{array}$ & $\begin{array}{l}2.1-1.9 \\
3.0-2.0 \\
6.3-4.9\end{array}$ & $\begin{array}{c}99.9-98 \\
91-97 \\
87-97\end{array}$ & $\begin{array}{c}{[9]} \\
{[13]} \\
{[38]}\end{array}$ \\
\hline Metal oxide & $\mathrm{CoOxSi}$ & 20 & $0.3-15$ & $0.4-0.3$ & $99.7-99.9$ & {$[11]$} \\
\hline Hybrid & $\begin{array}{l}\text { BTESE } \\
\text { MTES }\end{array}$ & $\begin{array}{c}30 \\
20^{\mathrm{a}}\end{array}$ & $\begin{array}{c}0.2 \\
0.3-3.5 *\end{array}$ & $\begin{array}{c}3.0 \\
4.7-2.5\end{array}$ & $\begin{array}{c}99 \\
93.7-83\end{array}$ & $\begin{array}{c}{[21]} \\
{[9]}\end{array}$ \\
\hline Zeolite & $\begin{array}{c}\text { MFI-S-1 } \\
\text { MFI-ZSM-5 } \\
\text { MFI-ZSM-5 } \\
\text { MFI-ZSM-5 }\end{array}$ & $\begin{array}{l}25 \\
25 \\
22 \\
20\end{array}$ & $\begin{array}{c}0.5 \\
0.5 \\
3.8 * \\
0.3-15\end{array}$ & $\begin{array}{c}0.12 \\
1.1 \\
0.70 \\
4.5-9.8\end{array}$ & $\begin{array}{c}75 \\
93 \\
99 \\
99.5-74\end{array}$ & $\begin{array}{c}{[39]} \\
{[40]} \\
{[41]} \\
{[8]}\end{array}$ \\
\hline
\end{tabular}

${ }^{\mathrm{a}}$ Feed pressurizing up to 7 bar and permeate vacuum pumping; ${ }^{\mathrm{b}}$ Pressure difference $(\Delta \mathrm{P})$ of $<1$ bar across the membrane; * Sea water.

Figure 6. Permeate salt concentration as a function of the feed salt concentration at $22{ }^{\circ} \mathrm{C}$.

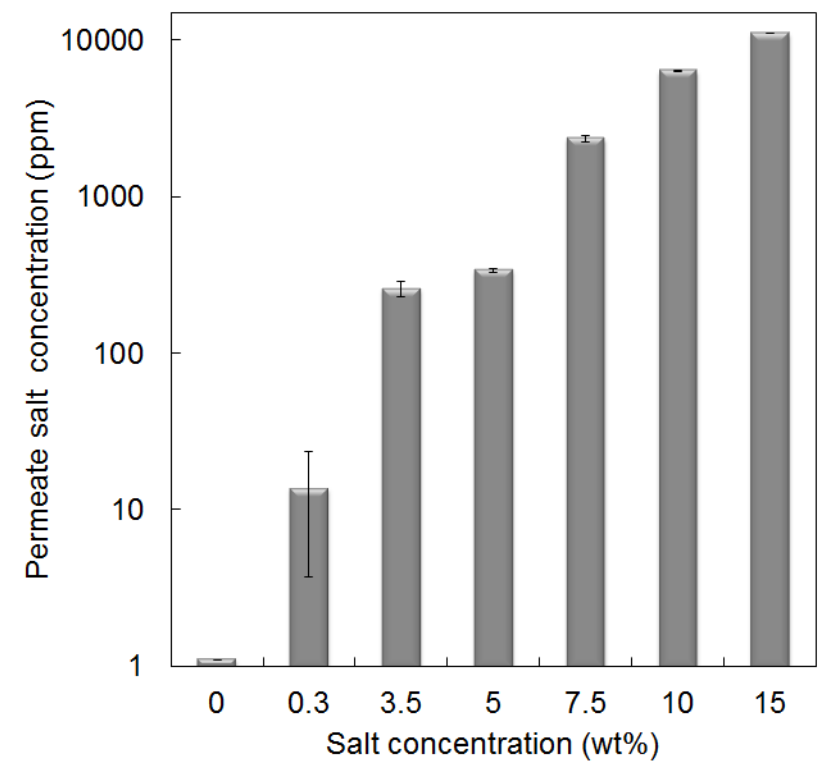

One major concern of the membrane performance is their long term stability. Long term membrane operation and stability was conducted using $\mathrm{NaCl} 3.5 \mathrm{wt} \%$ condition at $22{ }^{\circ} \mathrm{C}$ after the membrane desalination tests. As can be seen from Figure 5 that both flux and rejection have dramatically declined after the membranes were tested in $15 \mathrm{wt} \%$ feed solution $\left(1.6 \mathrm{~kg} \mathrm{~m}^{-2} \mathrm{~h}^{-1}, 89 \%\right)$. As a result, the membranes were washed with a copious amount of water to ensure that any salt residues and blockages were removed. Figure 7 shows the membrane water flux and salt rejection over the $250 \mathrm{~h}$ of test period. Preliminary stability results demonstrate that the membranes were reasonably stable for the first $150 \mathrm{~h}$ with water fluxes of approximately $8.5 \mathrm{~kg} \mathrm{~m}^{-2} \mathrm{~h}^{-1}$ after which a gradual decay in the fluxes had occurred reaching $6.7 \mathrm{~kg} \mathrm{~m}^{-2} \mathrm{~h}^{-1}$ for the $250 \mathrm{~h}$ test. The reduction in water fluxes could be attributed to the blocking of hydrated salt ions in microporous constrictions as discussed above. 
Interestingly, the flux at initial times (Figure 7) was measured slightly higher than the flux recorded previously as shown in Figure 5 after the washing procedure. The results of the long term stability suggest that the membrane matrices may be undergoing textural structural changes and/or a build-up of salt residues causing pore blockages. Nevertheless, this long term testing successfully demonstrated that the membranes are still capable of separating saline water at this treatment condition. Of particular attention, the integrity of the $\mathrm{pH} 6$ silica film was not affected, as salt rejections remained greater than $99 \%$ at all times.

Figure 7. Water fluxes and salt rejection of the membrane as a function of exposure time over $250 \mathrm{~h}$ in $3.5 \mathrm{wt} \%$ feed saline solution at $22{ }^{\circ} \mathrm{C}$.

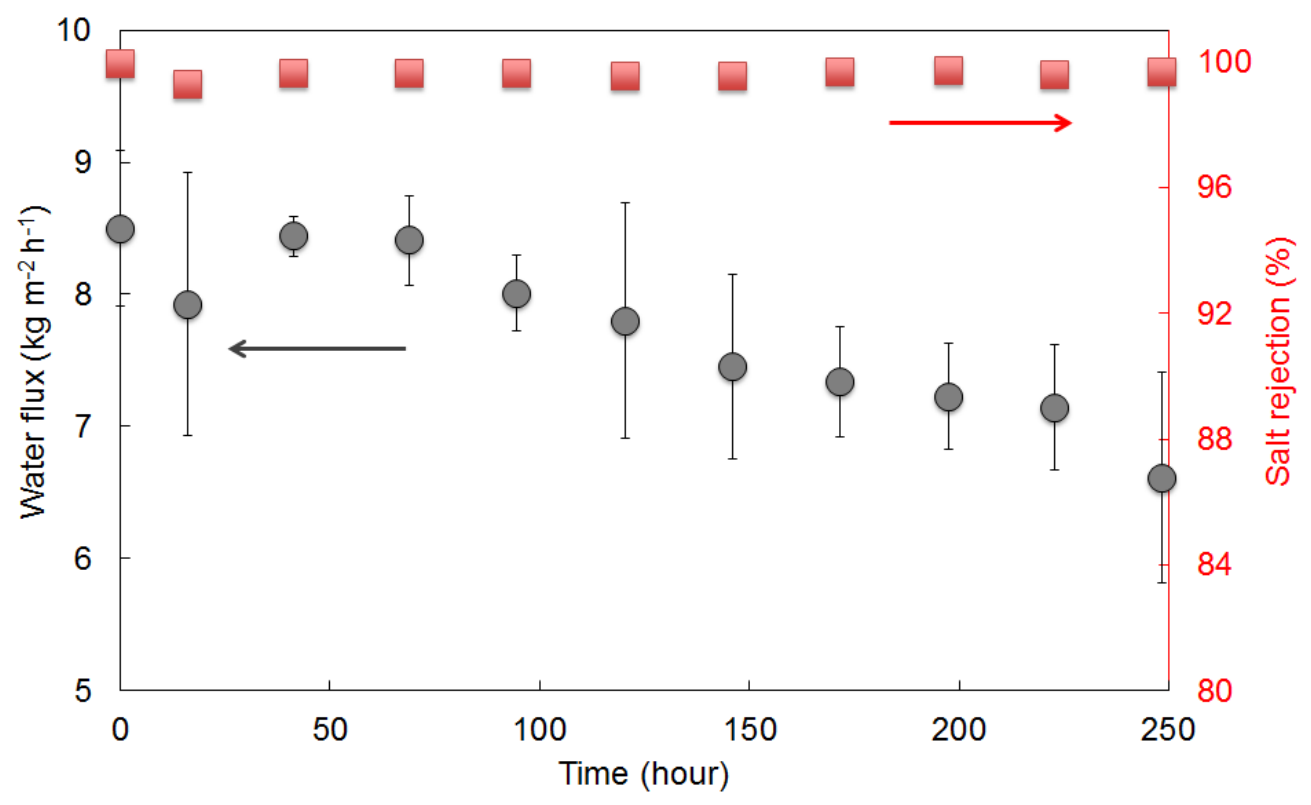

In this work, the membrane was clearly able to provide a selective barrier between the water molecule and the hydrated salt ions. However, as shown by the $\mathrm{N}_{2}$ isotherm (Figure 3), this membrane material pH 6 silica has a combination of micro and mesoporous texture with an average pore size measured at $27 \AA$, which is obviously much larger than the kinetic diameter of the permeating salt ions in this study. To further understand these results, Figure 8a displays the pores size distribution (PSD) of this membrane material (calcined bulk xerogel) based on the $\mathrm{N}_{2}$ isotherms discussed above. The PSD consisted of both microporous $(<2 \mathrm{~nm})$ and mesoporous pores $(2-10 \mathrm{~nm})$. It is important to bear in mind that the properties of deposited thin films may be quite different from bulk xerogels due to non-equivalent gelation and drying conditions [42]. Even though the properties of the xerogels and the thin-layer films are non-equivalent, the membrane materials in the form of xerogels are often used as a qualitative comparison of pore size distribution and pore evolution $[17,18,25,43,44]$ due to the ease of sample synthesis and characterization.

To further assess the performance of the membranes, Figure $8 \mathrm{~b}$ shows a schematic of the $\mathrm{pH} 6$ silica films in this work. Essentially silica films have smaller pore sizes than the bulk xerogel samples, which is evidenced by the higher salt rejection (Figures 5 and 7). If the silica pores were all mesoporous, then it is very likely that the membranes would not be able to reject the salt ions. It is known that amorphous silica possess a trimodal PSD consisting of small $3 \AA$ and large 8 and $12 \AA$ 
pore sizes as determined by positron annihilation spectroscopy [45]. Therefore, the membrane results in this work suggest that the salt rejection into the amorphous $\mathrm{pH} 6$ silica membranes was controlled by a percolative pathway containing constrictions below the size of hydrated salt ions $\left(\mathrm{Na}^{+}: \mathrm{d}_{\mathrm{k}}=7.2 \AA\right.$ and $\left.\mathrm{Cl}^{-}: \mathrm{d}_{\mathrm{k}}=6.6 \AA\right)[12,46]$ and above water $\left(\mathrm{d}_{\mathrm{k}}=2.6 \AA\right)$. However, silica films may also contain percolative pathways composed of mesoporous regions linked to microporous constrictions or to another mesoporous region. In view of the small amount of salt permeated through the membrane, it is evident that a small number of mesoporous percolative pathways ( $>7.2 \AA$ ) were present in the pH 6 silica film.

Figure 8. (a) Pore size distribution the xerogel sample using the density function theory method with inset displaying between 10 to $20 \AA$ and (b) Schematic illustrating percolative porous pathway and diffusions of water and hydrated salt ions through the pores of the silica matrix with the red halos representing the location of the microporous constrictions.
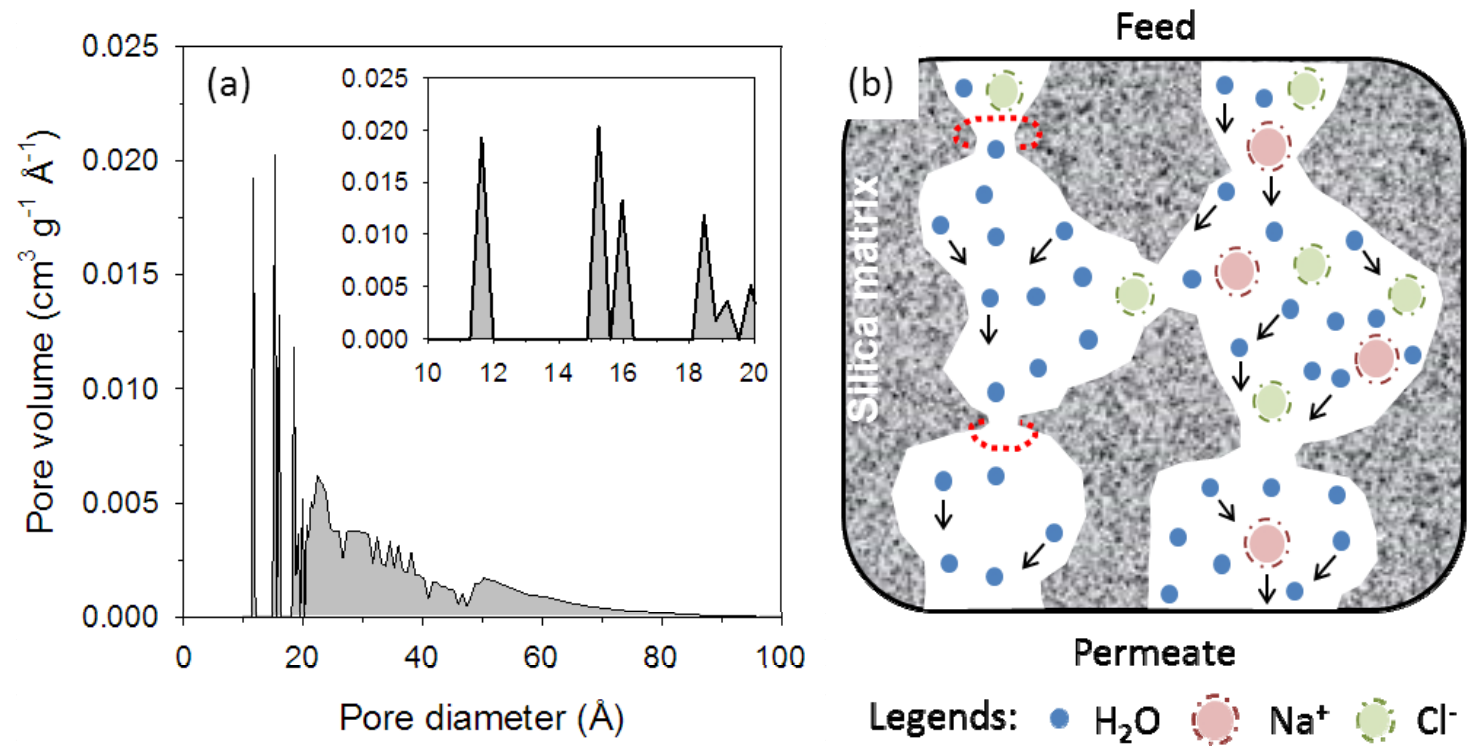

\section{Conclusions}

Mesoporous silica membranes have been successfully fabricated by dip-coating deposition of silica sol prepared from a two-step sol-gel process. $\mathrm{pH} 6$ condition was chosen, as synthesized sample produced the lowest silanol concentration, a requirement to obtain hydro-stable silica membranes. Hence, $\mathrm{pH} 6$ silica membranes delivered high water fluxes and salt rejection at $9.5 \mathrm{~kg} \mathrm{~m}^{-2} \mathrm{~h}^{-1}$ (salt rejection $99.6 \%$ ) and $6.8 \mathrm{~kg} \mathrm{~m}^{-2} \mathrm{~h}^{-1}(98.2 \%)$ for the 0.3 and $3.5 \mathrm{wt} \%$ saline solutions, respectively. Furthermore, the membranes can effectively produce potable water in these conditions achieving permeate salt concentration of less than $600 \mathrm{ppm}$. In addition, the tested membrane was reasonably stable for the first $150 \mathrm{~h}$ after which a gradual decay in the fluxes was observed resulting in approximately $6 \mathrm{~kg} \mathrm{~m}^{-2} \mathrm{~h}^{-1}$ at the $250 \mathrm{~h}$, albeit with salt rejections, were calculated to be greater than $99 \%$ at all times. The flux reduction was attributed to the blocking hydrated salt ions in the constrictions of the micropores in the amorphous silica film. Overall, the membrane performance exceeded the expectations for silica-based membranes reported in the literature thus far. 


\section{Acknowledgments}

Muthia Elma specially thanks for the scholarship provided by the University of Queensland. The authors acknowledge financial support from the Australian Research Council (DP110101185). The authors would like to thank Julius Motuzas for the SEM analysis work.

\section{Conflict of Interest}

The authors declare no conflict of interest.

\section{References}

1. World Health Organization and United Nations International Children's Fund. Progress on sanitation and drinking-water in joint monitoring programme for water supply and sanitation. 2010. Avaliable online: http://www.who.int/water_sanitation_health/monitoring/en/ (aceessed on 5 July 2013).

2. Foerch, W.; Althoff, I.; Foerch, G. Water demand. In Encyclopedia of Environment and Society, 1st ed.; Robbins, P., Ed.; SAGE Publications, Inc.: Thousand Oaks, CA, USA, 2007; Volume 24, pp. 1922 and 2736.

3. Global Water Intelligence Global Water Summit. Available online: http://www. globalwaterintel.com/archive/10/2/market-insight/2009-global-water-awardsmembrane-desalinationplant-year.html (accessed on 5 July 2013).

4. Elimelech, M.; Phillip, W.A. The future of seawater desalination: Energy, technology, and the environment. Science 2011, 333, 712-717.

5. Lee, K.P.; Arnot, T.C.; Mattia, D. A review of reverse osmosis membrane materials for desalination-development to date and future potential. J. Membr. Sci. 2011, 370, 1-22.

6. Pina, M.P.; Mallada, R.; Arruebo, M.; Urbiztondo, M.; Navascués, N.; de la Iglesia, O.; Santamaria, J. Zeolite films and membranes. Emerging applications. Microporous Mesoporous Mater. 2011, 144, 19-27.

7. Swenson, P.; Tanchuk, B.; Gupta, A.; An, W.; Kuznicki, S.M. Pervaporative desalination of water using natural zeolite membranes. Desalination 2012, 285, 68-72.

8. Drobek, M.; Motuzas, J.; Julbe, A.; Ding, L.; Yacou, C.; Diniz da Costa, J.C. Long term pervaporation desalination of tubular mfi zeolite membranes. J. Membr. Sci. 2012, 415-416, 816-823.

9. Duke, M.C.; Mee, S.; Diniz da Costa, J.C. Performance of porous inorganic membranes in non-osmotic desalination. Water Res. 2007, 41, 3998-4004.

10. Elma, M.; Yacou, C.; Wang, D.K.; Smart, S.; Diniz da Costa, J.C. Microporous silica based membranes for desalination. Water 2012, 4, 629-649.

11. Lin, C.X.C.; Ding, L.P.; Smart, S.; Diniz da Costa, J.C. Cobalt oxide silica membranes for desalination. J. Colloid Interface Sci. 2012, 368, 70-76.

12. Lin, J.; Murad, S. A computer simulation study of the separation of aqueous solutions using thin zeolite membranes. Mol. Phys. 2001, 99, 1175-1181. 
13. Wijaya, S.; Duke, M.C.; Diniz da Costa, J.C. Carbonised template silica membranes for desalination. Desalination 2009, 236, 291-298.

14. Battersby, S.; Smart, S.; Ladewig, B.; Liu, S.; Duke, M.C.; Rudolph, V.; Diniz da Costa, J.C. Hydrothermal stability of cobalt silica membranes in a water gas shift membrane reactor. Sep. Purif. Technol. 2009, 66, 299-305.

15. Gu, Y.; Oyama, S.T. Permeation properties and hydrothermal stability of silica-titania membranes supported on porous alumina substrates. J. Membr. Sci. 2009, 345, 267-275.

16. Igi, R.; Yoshioka, T.; Ikuhara, Y.H.; Iwamoto, Y.; Tsuru, T. Characterization of co-doped silica for improved hydrothermal stability and application to hydrogen separation membranes at high temperatures. J. Am. Ceram. Soc. 2008, 91, 2975-2981.

17. Miller, C.R.; Wang, D.K.; Smart, S.; Diniz da Costa, J.C. Reversible Redox Effect on Gas Permeation of Cobalt Doped Ethoxy Polysiloxane (ES40) Membranes. Sci. Rep. 2013, 3, 1648:1-1648:6.

18. Yacou, C.; Smart, S.; Diniz da Costa, J.C. Long term performance cobalt oxide silica membrane module for high temperature $\mathrm{H}_{2}$ separation. Energy Environ. Sci. 2012, 5, 5820-5832.

19. Chua, Y.T.; Lin, C.X.C.; Kleitz, F.; Zhao, X.S.; Smart, S. Nanoporous organosilica membrane for water desalination. Chem. Commun. 2013, 49, 4534-4536.

20. Castricum, H.L.; Sah, A.; Kreiter, R.; Blank, D.H.A.; Vente, J.F.; Ten Elshof, J.E. Hybrid ceramic nanosieves: Stabilizing nanopores with organic links. Chem. Commun. 2008, 1103-1105.

21. Xu, R.; Wang, J.; Kanezashi, M.; Yoshioka, T.; Tsuru, T. Development of robust organosilica membranes for reverse osmosis. Langmuir 2011, 27, 13996-13999.

22. Duke, M.C.; Diniz da Costa, J.C.; Do, D.D.; Gray, P.G.; Lu, G.Q. Hydrothermally robust molecular sieve silica for wet gas separation. Adv. Funct. Mater. 2006, 16, 1215-1220.

23. Tsuru, T.; Igi, R.; Kanezashi, M.; Yoshioka, T.; Fujisaki, S.; Iwamoto, Y. Permeation properties of hydrogen and water vapor through porous silica membranes at high temperatures. AIChE J. 2011, 57, 618-629.

24. International Organization for Standardization. Pore Size Distribution and Porosity of Solid Materials by Mercury Porosimetry and Gas Adsorption: Part 3; International Organization for Standardization: Geneva, Switzerland, 2007.

25. Tran, T.H.Y.; Schut, H.; Haije, W.G.; Schoonman, J. Structural characterization and porosity analysis in self-supported porous alumina-silica thin films. Thin Solid Films 2011, 520, 30-34.

26. Evans, R. Nature of the iquid-vapour interface and other topics in the statistical mechanics of non-uniform, classical fluids. Adv. Phys. 1979, 28, 143-200.

27. Lastoskie, C.; Gubbins, K.E.; Quirke, N. Pore size distribution analysis of microporous carbons: A density functional theory approach. J. Phys. Chem. 1993, 97, 4786-4796.

28. Wojdyr, M. Fityk: A general-purpose peak fitting program. J. Appl. Crystallogr. 2010, 43, $1126-1128$.

29. Bertoluzza, A.; Fagnano, C.; Antonietta Morelli, M.; Gottardi, V.; Guglielmi, M. Raman and infrared spectra on silica gel evolving toward glass. J. Non-Cryst. Solids 1982, 48, 117-128.

30. Brinker, C.J.; Scherer, G.W. Sol-Gel Science: The Physics and Chemistry of Sol-Gel Processing, 1st ed.; Academic Press: Boston, MA, USA, 1990; p. 908.

31. Brinker, C.J.; Keefer, K.D.; Schaefer, D.W.; Ashley, C.S. Sol-gel transition in simple silicates. J. Non-Cryst. Solids 1982, 48, 47-64. 
32. Brinker, C.J.; Keefer, K.D.; Schaefer, D.W.; Assink, R.A.; Kay, B.D.; Ashley, C.S. Sol-gel transition in simple silicates II. J. Non-Cryst. Solids 1984, 63, 45-59.

33. Gao, X.; Diniz da Costa, J.C.; Bhatia, S.K. The transport of gases in a supported mesoporous silica membrane. J. Membr. Sci. 2013, 438, 90-104.

34. Gao, X.; Bonilla, M.R.; Diniz da Costa, J.C.; Bhatia, S.K. The transport of gases in a mesoporous $\gamma$-alumina supported membrane. J. Membr. Sci. 2013, 428, 357-370.

35. Huang, P.; Xu, N.; Shi, J.; Lin, Y.S. Characterization of asymmetric ceramic membranes by modified permporometry. J. Membr. Sci. 1996, 116, 301-305.

36. Cheraitia, A.; Ayral, A.; Julbe, A.; Rouessac, V.; Satha, H. Synthesis and characterization of microporous silica-alumina membranes. J. Porous Mater. 2010, 17, 259-263.

37. Uhlmann, D.; Smart, S.; Diniz da Costa, J.C. High temperature steam investigation of cobalt oxide silica membranes for gas separation. Sep. Purif. Technol. 2010, 76, 171-178.

38. Ladewig, B.P.; Tan, Y.H.; Lin, C.X.C.; Ladewig, K.; Diniz da Costa, J.C.; Smart, S. Preparation, characterization and performance of templated silica membranes in non-osmotic desalination. Materials 2011, 4, 845-856.

39. Li, L.; Dong, J.; Nenoff, T.M.; Lee, R. Desalination by reverse osmosis using mfi zeolite membranes. J. Membr. Sci. 2004, 243, 401-404.

40. Li, L.; Liu, N.; McPherson, B.; Lee, R. Enhanced water permeation of reverse osmosis through MFI-type zeolite membranes with high aluminum contents. Ind. Eng. Chem. Res. 2007, 46, 1584-1589.

41. Duke, M.C.; O’Brien-Abraham, J.; Milne, N.; Zhu, B.; Lin, J.Y.S.; Diniz da Costa, J.C. Seawater desalination performance of mfi type membranes made by secondary growth. Sep. Purif. Technol. 2009, 68, 343-350.

42. Brinker, C.J.; Hurd, A.J.; Ward, K.J. Fundamentals of Sol-Gel Thin-Film Formation; Wiley: New York, NY, USA, 1988.

43. Uhlmann, D.; Liu, S.; Ladewig, B.P.; Diniz da Costa, J.C. Cobalt-doped silica membranes for gas separation. J. Membr. Sci. 2009, 326, 316-321.

44. Uhlmann, D.; Smart, S.; Diniz da Costa, J.C. $\mathrm{H}_{2} \mathrm{~S}$ stability and separation performance of cobalt oxide silica membranes. J. Membr. Sci. 2011, 380, 48-54.

45. Duke, M.C.; Pas, S.J.; Hill, A.J.; Lin, Y.S.; Diniz da Costa, J.C. Exposing the molecular sieving architecture of amorphous silica using positron annihilation spectroscopy. Adv. Funct. Mater. 2008, 18, 3818-3826.

46. Li, L.X.; Dong, J.H.; Nenoff, T.M.; Lee, R. Reverse osmosis of ionic aqueous solutions on a mfi zeolite membrane. Desalination 2004, 170, 309-316.

(C) 2013 by the authors; licensee MDPI, Basel, Switzerland. This article is an open access article distributed under the terms and conditions of the Creative Commons Attribution license (http://creativecommons.org/licenses/by/3.0/). 